\title{
BUDISMO Y FILOSOFÍAS AMERINDIAS \\ EN EL ANTROPOCENO. SERES NO HUMANOS EN LA ACTUAL CRISIS ECOLÓGICA
}

\author{
Buddhism and Amerindian philosophies \\ in the Anthropocene. More-than-human beings \\ in the current ecological crisis
}

Florencia Tola, CONICET / Universidad de Buenos Aires, Argentina Juan Restrepo, Universidad del Valle, Colombia

\begin{abstract}
Resumen: Este artículo se centra en el nuevo paradigma cosmológico que representa el Antropoceno a partir del análisis de narrativas en las que los seres no humanos adquieren un lugar central. Si bien ciertas narrativas del Antropoceno permiten comprender al humano en cohabitación con otros seres, las metafísicas amerindias y el budismo, por su parte, aportan en la reflexión sobre la agencia de seres no humanos. Este artículo pretende contribuir a los debates sobre la crisis planetaria desde la lectura comparada de dos narrativas que divergen de los discursos científicos sobre el Antropoceno y amplían sus alcances.
\end{abstract}

Palabras clave: Antropoceno, metafísicas amerindias, budismo.

\begin{abstract}
This article focuses on the new cosmological paradigm represented by the Anthropocene, from the analysis of narratives in which non-human beings acquire a central place. If certain Anthropocene narratives allow us to understand the human in cohabitation with other beings, Amerindian metaphysics and Buddhism contribute to this reflection on the agency of non-human beings. This article aims to contribute to the debate on the planetary crisis, from the comparative reading of two narratives that diverge from scientific discourse on the Anthropocene and broaden its scope.
\end{abstract}

Keywords: Anthropocene, Amerindian metaphysics, Buddhism. 


\section{Introducción}

El debate sobre la actual crisis ecológica se intensificó a raíz de sucesos tales como los incendios del Amazonas y Australia, el derretimiento de las criósfera y el aumento paulatino de la temperatura y de las cantidades de dióxido de carbono enviadas a la atmósfera, que hacen irrespirable el aire, entre otros. Esta crisis generó el surgimiento de una categoría que vincula la actividad humana con los acontecimientos mencionados: Antropoceno. Referirse al Antropoceno significa adentrarse en la crisis ecológica contemporánea en la que se halla inserta la vida humana y no humana. Reflexionar sobre el Antropoceno es pensar un tiempo crítico en el que la tierra funciona como un sistema no análogo donde las condiciones que se avecinan generan situaciones nunca antes vividas, al menos para el humano. Como expresan algunos autores:

[...] los habitantes humanos de nuestro planeta enfrentarán, en un lapso de unas pocas décadas, cambios globales de un alcance y una velocidad sin precedentes [...]. Por ejemplo, la actual intensidad de pérdida de biodiversidad no es comparable con nada que haya sucedido desde la quinta extinción masiva, hace unos 65 millones de años [...]. Así que más que una mera crisis ecológica, el Antropoceno conlleva un nuevo régimen geológico de existencia para la Tierra y una nueva condición humana (Hamilton, Bonneuil y Gemene, 2015: 4). ${ }^{1}$

Según Danowski y Viveiros de Castro (2019), el Antropoceno puede ser comprendido como una época de profunda ansiedad en la que emergen diversos relatos vinculados a una temática central, presente en numerosas mitologías: el fin del mundo. Viveiros de Castro (2019) argumenta que el Antropoceno implica un «cambio cosmológico» o una segunda revolución copernicana en el ámbito humano por la cual surge una relación con la Tierra que obliga a redefinir lo «humano». En este artículo nos proponemos dar cuenta de que aquello que se juega en el Antropoceno no es solo una variante de las diferentes narrativas del fin del mundo. Nos preguntaremos en qué consiste esta nueva relación que el Antropoceno suscita y si esta conlleva una comprensión diferente tanto de la tierra como de la situación humana. Para ello reflexionaremos sobre una de las variaciones narrativas que está emergiendo en los discursos sobre el Antropoceno: el advenimiento de una comprensión diferente de los seres no humanos. Este punto constituye una de las paradojas centrales del Antropoceno: en la época signada por la disminución de las entidades que habitan el planeta, las ciencias humanas comienzan a prestar atención a aquello que fue considerado como desprovisto de agencia (Latour, 2012 [1991]). Nuestro interés es explorar este nuevo paradigma cosmológico a partir de diversas narrativas en las que la presencia de los no humanos adquiere un lugar central. Desarrollaremos la idea de que el Antropoceno permite, en las ciencias humanas, comenzar a comprender al ser humano en interdependencia con los no humanos que, desde la modernidad, no fueron tomados en consideración. Este cambio de perspectiva que caracteriza parte de la antropología contemporánea fue expresado en metafí-

1. Las traducciones son nuestras, salvo que se citen textos traducidos. 
sicas no occidentales - tales como la amerindia y la budista - para las que la agencia se extiende hacia seres más allá de los humanos. Luego de una breve introducción al debate del Antropoceno, nos detendremos en algunos rasgos centrales de estas otras metafísicas.

\section{El Antropoceno como problema}

Si bien el término Antropoceno proviene de las ciencias geológicas y climatológicas, el campo de discusión que abre resulta provechoso para pensar la crisis ecológica en un nivel filosófico y antropológico, como lo demuestran los trabajos de Stengers (2017), Latour (2017), Haraway (2016), Chakrabarty (2009) y Danowski y Viveiros de Castro (2019), entre otros.

Antropoceno es una categoría propuesta por Crutzen y Stoermer (2000) para caracterizar, desde el ámbito geológico, el advenimiento de una nueva época. A grandes rasgos, lo que defiende este concepto es el cambio en el peso de la influencia de los procesos humanos en el funcionamiento del sistema Tierra. Algo que parece obvio, pero no lo es tanto si tenemos en cuenta que desde el Holoceno el ser humano ha vivido en un entorno relativamente estable sobre el cual ha estado ejerciendo un influjo moderado. Aun cuando el humano siempre haya transformado el entorno, una característica única del Antropoceno es la influencia que ejerce en la composición y el funcionamiento de la Tierra en cuanto que sistema.

En el Antropoceno el impacto humano sobre el planeta adquiere una fuerza tan determinante como la de las placas tectónicas. Esta influencia es visible en la composición de la atmósfera, en la creciente acidificación de los océanos y en la expansiva desertificación o extensión del monocultivo en las tierras que antes eran selvas, hecho que recuerda que el Antropoceno no se restringe a un mero cambio climático (Rockstrom et al., 2009). Como expresa Haraway: «Es más que cambio climático; es también la cantidad extraordinaria de tóxicos químicos, minería, polución nuclear, agotamiento de ríos y lagos en la superficie de la Tierra, simplificación de los ecosistemas, vastos genocidios de personas y otras criaturas» (2016: 100).

\subsection{Maneras de comprender el Antropoceno}

Según Hamilton, Bonneuil y Gemene (2015), es posible encontrar en el término Antropoceno tres acepciones principales. Por un lado, el concepto propone un nuevo intervalo en la historia geológica del planeta. Las comisiones de estratigrafía dedicadas al estudio de los sedimentos marítimos y terrestres intentan dilucidar la posibilidad de decretar un intervalo que marca un cambio radical de época. Una segunda acepción se refiere al dramático cambio que sufre el planeta según la ciencia del sistema Tierra. La climatología, la ecología y la geoquímica indican que el impacto de las acciones humanas genera un cambio en el funcionamiento del planeta. Así, según sostienen aquellos autores, «aún considerada geológica en su sentido más amplio, [esta definición] no busca evi- 
dencia solo en los estratos de roca. Con sus lentes más amplios, la ciencia del sistema Tierra experimenta un cambio y deja su estado del Holoceno [...] para entrar en un nuevo estado: el Antropoceno» (Ibídem: 2). Y una tercera definición se vincula con la relación que se entabla entre el ser humano y la naturaleza, una relación nueva en la cual la influencia humana puede compararse con procesos que dan forma a la tierra; resuenan aquí las palabras de Chakrabarty (2009), para quien el ser humano se ha transformado en un agente geológico. Aun si la comisión de estratigrafía dictaminara que no se pueden hallar datos que demuestren una influencia considerable en los estratos geológicos, el Antropoceno puede continuar siendo un concepto pertinente según la segunda y la tercera definición (Hamilton, Bonneuil y Gemenne, 2015: 3). De esta manera, la crítica que articulan Finney y Edwards (2015) acerca de lo impreciso que resulta el Antropoceno desde el punto de vista estratigráfico no requiere que se rechace el concepto en sí, si es comprendido como una instancia que se relaciona con los cambios generados en el sistema Tierra y con el cambio de paradigma cosmológico, en el cual «el sentido mismo de las palabras "mundo" y "punto de vista" y la identidad del "perceptor" se encuentran en disputa» (Viveiros de Castro, 2019: S296). ${ }^{2}$

Es en esta tercera acepción que situamos la presente reflexión: en la manera en que diversas narrativas que emergieron en las ciencias humanas muestran una sensibilidad particular frente a los seres no humanos y destacan su agencia. Estas narrativas envuelven una ontología diferente de aquella que legó la modernidad y que, en algunos puntos, se cruzan con perspectivas ajenas y distantes en el tiempo y el espacio, tales como las propuestas por las metafísicas amerindias y el budismo. ${ }^{3}$ El ejercicio que nos proponemos es un diálogo en el que destacamos un rasgo crucial para evaluar la emergencia de un nuevo paradigma cosmológico que abra el espacio para una cohabitación diferente entre humanos y no humanos.

A continuación, a través de tres ejemplos (Antropoceno parche, Gaia y Chthuluceno) comentaremos cómo surge en narrativas críticas del Antropoceno la posibilidad de pensar otras agencias. Estas perspectivas constituyen ejemplos más que modelos (Viveiros de Castro, 2019), en el sentido de que permiten mantener el campo abierto: la excepción.

2. Consideramos pertinente la pregunta de Trischler (2017) acerca de si el Antropoceno puede ser entendido como concepto cultural más que geológico. Gran parte de la operatividad del concepto radica, a nuestro entender, en que genera un espacio de intercambio entre disciplinas naturales y humanas.

3. En un intento por poner en valor formas no occidentales de pensamiento y especulación filosófica, utilizamos el término «metafísicas» en plural para referirnos a sistemas de pensamiento (tanto budista como amerindios) que crearon y crean ideas originales y conceptos, así como explicaciones para circunstancias diversas (animales que se ven como humanos, muertos que actúan en el mundo, seres no humanos que se comunican con los humanos y entre sí, etc.). Hablamos de metafísica en el sentido que expresa Viveiros de Castro en su diálogo con Peter Skafish, en cuanto que una actividad vital de todos los seres humanos. Parafraseando a Strathern cuando se refiere al concepto de cultura (pues lo mismo vale para la noción de metafísica): «lo lindo de la metafísica es que todos tenemos una, pero [...] todos la tenemos de un modo diferente [differently]» (Viveiros de Castro, en Skafish, 2016: 399). 


\section{Ejemplos}

\subsection{Antropoceno parche}

Este ejemplo constituye una propuesta metodológica para prestar atención a los territorios y a la modificación que se genera en ellos a partir de las prácticas del capitalismo tardío. Tsing (2017b) había planteado que la modificación humana en el Antropoceno se entendía mejor como un «Plantacioceno». Para ella, el carácter modificador del humano se vislumbra en el régimen de las plantaciones, introducido por primera vez en América, que se extendió no solo en la agricultura sino también en un régimen expansivo que involucra animales y combustibles alternativos, entre otros. Para Tsing, las plantaciones:

[...] apuntan a ecologías simplificadas diseñadas para crear propiedades para futuras inversiones [...] [;] las plantaciones matan los seres que no son considerados propiedad. Asimismo promueven nuevas ecologías de proliferación, la expansión inmanejable de la vida de las plantaciones en forma de enfermedad y polución [...] [;] la proliferación amenaza la vida en el planeta (Tsing, 2017b: 51).

Las plantaciones reducen la complejidad de los territorios y las formas de vida ensambladas, y producen simplificaciones modulares. Esto genera las proliferaciones que se ven representadas en virus, enfermedades e incendios. ${ }^{4} \mathrm{El}$ advenimiento del Antropoceno no es, para Tsing, un suceso que deba ser recibido con esperanza sino que ha de ser resistido. ${ }^{5}$ Constituye una amenaza a las ecologías multiespecie que se ensamblan a lo largo de la historia. Es por ello que Tsing sugiere que «Holoceno y Antropoceno no ofrecen una cronología singular, sino que apuntan a modos ecológicos divergentes, que coexisten a través del tiempo histórico. Para preservar la vida, se necesita conservar ecologías del Holoceno y para hacer esto se necesita prestar atención a ellas» (Tsing, 2017b: 54). Su proyecto requiere que la antropología se focalice en las socialidades multiespecie que se ensamblan en un territorio determinado. La distinción entre ecologías del Antropoceno y ecologías del Holoceno deja claro que los efectos de la «época del hombre» son preocupantes por el masivo empobrecimiento de las ecologías afectadas por las plantaciones. Es por ello por lo que su propuesta incita a llevar a cabo una antropología que tome en serio las formas de vida no humanas. La atención a los territorios y las socialidades multiespecie que en ellos suceden muestra parches donde el Antropoceno ocurre y se evidencia en sus

4. El caso de los incendios se palpa en los monocultivos de pinos en la zona del sur de Argentina como una de dichas proliferaciones feroces. Estas plantaciones se desarrollaron a partir de 1950 y se relacionan con una expansión de los incendios de la zona en proporciones preocupantes, principalmente porque presentan una simplificación de los ecosistemas. Véase Tozzini (2011).

5. Se hizo común dividir entre aquellos que proponen un Antropoceno «bueno» (con énfasis en la geoingeniería) y quienes se enlistan en los discursos apocalípticos. A Tsing no podríamos ubicarla en ninguno de los dos grupos. Las simplificaciones y violencias del Antropoceno son objeto de estudio, así como también las resistencias humanas y no humanas. 
simplificaciones ecológicas y las proliferaciones feroces, de las cuales Tsing habla con respecto a las plantaciones.

\subsection{Gaia, zona metamórfica}

La tesis de Gaia propuesta por Lovelock y Margulis (1974) da cuenta de la manera en que la Tierra puede ser comprendida como un sistema orgánico que genera las condiciones para la propagación de la vida misma. ${ }^{6}$ La introducción de esta perspectiva fue tomada con diferentes grados de exaltación y reticencia por parte de la comunidad científica. Para Latour, la tesis de Gaia se convierte en la oportunidad perfecta para disputar el Gran Divisor formulado, al menos, desde la modernidad (Latour, 2012 [1991]). Este Gran Divisor (naturaleza/cultura), según el pensador francés, debe concebirse como una operación. La bifurcación de la naturaleza en la que esta pasa a ser una esfera desprovista de agencia se logra por un proceso en el cual la ciencia moderna, al mismo tiempo que multiplica las agencias del mundo, purifica la modernidad de su proliferación. Por un lado, las ciencias ayudan a percibir objetos del mundo no conocidos, pero, por otro lado, la ciencia purifica las entidades del mundo y las declara pertenecientes al campo de la naturaleza donde no hay capacidad de actuar.

El proceso en el que diferentes entidades son declaradas como materiales y en el que les es negada agencia es un efecto secundario. En un primer momento, existe lo que Latour denomina «zona metamórfica», donde las entidades actúan y se relacionan entre sí. La purificación hace que las entidades sean efectos que pierden capacidad de actuar, ya que son determinados por las causas. En este proceso, toda causalidad o agencia será dictaminada como sobrenatural y netamente humana. Es precisamente este proceso de purificación lo que es puesto en cuestión con el Antropoceno. Retomando la alusión de Michel Serres (2004) según la cual la Tierra no solo se mueve, como descubre Galileo, sino que además se conmueve, Latour propone pensar los aportes de climatólogos y geólogos como una manera de comprender una zona metamórfica de intercambios entre humanos y no humanos.

Al mostrar los efectos que el ser humano tiene sobre la Tierra y al exponer las formas en que diferentes entidades reaccionan a la actividad humana, los científicos del Antropoceno proponen un nuevo relato que tanto Latour como Stengers relacionan con el advenimiento de Gaia. Esta zona metamórfica o Gaia no debe ser concebida como un mundo armonioso y equilibrado: Gaia está hecha de historia y no es inmutable. El Antropoceno pone de manifiesto las relaciones múltiples que componen al humano y obligan a actuar de modo diplomático con estas agencias no humanas. Latour invita a pensar desde estas zonas metamórficas del siguiente modo:

6. «La hipótesis de Gaia propuso que los seres vivos podrían regular colectivamente aspectos de su entorno abiótico global: la composición química de la atmósfera y los océanos y potencialmente también el clima» (Lenton et al., 2020: 248). 
Si es el mundo lo que nos interesa $-y$ ya no la naturaleza-, entonces hay que aprender a habitar aquello que podríamos Ilamar, tomando prestada una metáfora a la geología, una zona metamórfica, para captar, en una sola palabra todos los morfismos que deberemos registrar para seguir estas transacciones (Latour, 2017: 75).

\subsection{Monstruos y cíborgs, Chtuluceno}

Aunque Haraway y Latour convergen en la necesidad de habitar zonas metamórficas y argumentan la necesidad de pensar los problemas relacionados con el Antropoceno, la primera es crítica con esta categoría. Ella se pregunta cómo es posible que la actual época, en la cual es inimaginable pensarnos como individuos separados, tenga un nombre tan inapropiado como Antropoceno, que pone el acento en el anthropos. ¿Cómo concebir un mejor nombre para esta época en la que la catástrofe ecológica, la extinción masiva de seres y ensamblajes, exige replantear modelos basados en el individualismo? Haraway señala que en la propuesta del Antropoceno se refleja la pobreza de la imaginación y que seguimos girando en torno a una ontología antropocéntrica, y así:

Pese a su apoyo en modelación computarizada y en la teoría de los sistemas autopoiéticos, el Antropoceno se apoya mucho en lo que podemos pensar como una teoría de las relaciones «impensable», aquella del individualismo utilitario limitado - unidades preexistentes en competencia que toman aire de la atmósfera (Haraway, 2017: 49).

Según Haraway (1991), el sesgo tecnocrático de los geólogos y climatólogos que abanderan los discursos de Antropoceno debe criticarse, puesto que la manera como estos encaran el término tiene una tendencia a ofrecer soluciones como la geoingeniería, en la cual se magnifica la influencia humana sobre los procesos de la Tierra. La oposición crítica a esta perspectiva nace, para esta autora, de una necesidad de pensar los engendros, monstruos o cíborgs, que sitúan la experiencia humana en un ámbito morfológico ambiguo. Por esto, ella invita a dejar a un lado los sistemas autopoiéticos que son los pilares de las ciencias climáticas. Basándose en la química Lynn Margulis, Haraway propone pensar simpoiéticamente en el entramado de seres que se ayudan e influyen atravesando fronteras individuales y de especie. Estos lugares de entrecruzamiento, comunicación y relación son difícilmente percibidos por las teorías individualistas. El trabajo consiste, pues, en explicitar estas zonas y dar cuenta de la relacionalidad de la trama de la vida, por lo que Haraway propone un vocablo que preste atención a las pérdidas sin caer en el nihilismo ecológico: Chtuluceno, en honor al arácnido Pimoa chthulhu. Esta acepción es un llamado a los seres ctónicos, no a los héroes, que saben vincularsecon la tierra y con una multitud de especies.

Tras estas consideraciones presentaremos a continuación las dos metafísicas no occidentales que constituyen, a nuestro entender, aportes para pensar las relaciones con agencias no humanas, así como la interdependencia entre los seres. 


\section{Metafísicas amerindias: el Gran Chaco como ejemplo}

La etnografía amerindia de las últimas cuatro décadas desarrolló conceptos de gran productividad teórica para pensar las ontologías, las relaciones entre los existentes y las articulaciones entre identidad y alteridad. Animismo, perspectivismo y predación son algunas de las categorías y modelos que la etnografía de tierras bajas sudamericanas produjo y legó a la antropología. Si bien no nos detendremos en las bases etnográficas de estos conceptos, destacaremos que estos contienen implícita una metafísica según la cual la relación entre la identidad y la alteridad, yo y el otro, humanos y no humanos es crucial para la socialidad extendida y la constitución de sí en cuanto que eje de relaciones e interdependencias.

En la década de los noventa, Philippe Descola (2014: 198-217) desarrolló el concepto de animismo y lo consideró como una forma de objetivación de los seres de la naturaleza. Años después (2005), el animismo fue conceptualizado por el mismo autor como una ontología, es decir, un modo de identificación entre humanos y no humanos en función de las continuidades o discontinuidades entre interioridad y fisicalidad. El animismo como ontología radica en que los animales y otras entidades no humanas son considerados poseedores de intencionalidad, afectos, agencia y vida social análogos a los de los humanos. La noción de persona se expande más allá de los humanos y se constituye como el simétrico inverso de la ontología naturalista: la occidental, que se funda en el Gran Divisor. En las sociedades amerindias la distribución de la interioridad va más allá de la esfera de los seres humanos y los principios diferenciadores pasan por la fisicalidad; así, humanos y no humanos poseen una interioridad semejante y lo que varía son sus fisicalidades. Las ontologías amerindias tienden a atribuir la posición de sujeto a un gran número de seres, y en este universo cargado de sujetos intencionales y agentivos, las relaciones son de gran interdependencia.

El animismo reposa en la idea de que la propia apariencia, percibida por un otro, es una cuestión de perspectiva. La identidad del cuerpo depende de la naturaleza del cuerpo que percibe. El cuerpo no puede ser concebido por fuera de la relación necesaria con un sujeto testigo. En este punto, el animismo se entrelaza con el perspectivismo de Viveiros de Castro (1996). El perspectivismo, en sus bases, postula que la manera en que los seres humanos perciben a los animales y a los otros difiere de la manera en que los otros seres se perciben a sí mismos y a los otros. Si la interioridad coincide entre los diversos seres, aquello que varía es su capacidad de perspectiva. En el perspectivismo no existiría ninguna esencia propia a cada entidad, ya que todo dependería del modo en que una entidad se vea y sea vista. En este punto radica una de las cuestiones metafísicas centrales del perspectivismo: la ausencia de esencias absolutas y la inexistencia de un mundo externo, existente per se, listo para ser percibido.

El concepto de predación ontológica se asocia con la idea de que el sí mismo requiere para su existencia la apropiación del otro. El socius opera de la misma manera: el interior se reproduce a partir de la captura previa de un alter que es transformado en parte constitutiva del socius. En el corazón de esta filosofía 
de la predación se encuentra la noción misma de enemigo. El sí mismo requiere para su existencia el paso por la alteridad, por ese otro que suele ser visto como un enemigo. Uno de los aspectos recurrentes del «complejo simbólico» amazónico (Viveiros de Castro, 2002: 290) relativo a la relación matador-víctima es el aumento del «capital ontológico» del matador. Tal como varias etnografías lo refieren, el asesino anexa en su cuerpo recursos simbólicos provenientes del enemigo obtenidos luego de incursiones guerreras, recursos con los que, siempre según el autor, el matador asimila del enemigo su posición de enemigo o los signos de su alteridad (Ídem). Así, la socialidad amerindia se definiría por «esos mismos predicados» provenientes, vía prácticas predatorias, del exterior, del enemigo, de la alteridad (Ibídem: 291).

Estos tres conceptos y teorías contienen implícita la idea de interdependencia y de relación necesaria entre los existentes. Es decir, por un lado, para pensar el cuerpo y la persona no es posible hacer uso de la noción de individuo ni de la idea de que el cuerpo sea la sede de una individualidad. Por otro lado, así como la persona se constituye a partir de sus relaciones con otros, la sociedad también requiere de la alteridad para constituirse. En un plano metafísico, el universo, la sociedad y la persona dependen de que se generen y regeneren relaciones de cortesía y diplomacia para perpetuarse. Animales, plantas, fenómenos atmosféricos, montañas, muertos, aguadas y espíritus-dueños son algunas de las subjetividades entre quienes es preciso tejer relaciones políticas que garanticen la continuidad de una sociedad plural. Reglas morales no respetadas, excesos en el abastecimiento, rompimiento de fórmulas de etiqueta bien pautadas pueden ser las causas de la destrucción del mundo, en términos físicos y metafísicos. Esta destrucción latente y potencial lejos está de ser un final de mundo al que se llega por la irreversibilidad de procesos comenzados por el accionar, única y exclusivamente, de los seres humanos. Esta posición daría al humano un lugar privilegiado en el universo, sin bien un lugar difícil de sostener en las ontologías relacionales en las que la trama del mundo está compuesta por una diversidad de entidades entrelazadas.

En el caso específico de los tobas o qom, pueblo indígena chaqueño, ${ }^{7}$ la morfología del mundo es la consecuencia de la intencionalidad de una pluralidad de seres más allá de los humanos (Tola et al., 2019). ${ }^{8}$ Desarrollaremos algu-

7. El Gran Chaco es el tercer gran territorio biogeográfico y morfoestructural de América Latina, después del Amazonas y el Sistema Sabánico Sudamericano. Ocupa más de $1.000 .000 \mathrm{~km}^{2}$ y se extiende a lo largo de cuatro países (Argentina, Bolivia, Paraguay y Brasil). En esta región viven individuos pertenecientes a 24 pueblos indígenas que tenían una tradición cazadora-recolectora y se organizaban en bandas y tribus. Con la ocupación de los territorios del Chaco argentino por las fuerzas militares a finales de 1800 y tras la colonización, los indígenas fueron forzados a instalarse en comunidades agrícolas y a trabajar en obrajes madereros e ingenios azucareros. Hoy en día, los tobas, cuya población ronda las 126.000 personas, viven en comunidades rurales en el Gran Chaco o en barrios ubicados en los márgenes de grandes urbes.

8. La información referida al pueblo toba o qom del Gran Chaco es fruto del trabajo de campo etnográfico llevado a cabo por Florencia Tola. Desde 1997, ella realiza investigaciones con miembros de más de cinco comunidades del centro y centro-sur de la provincia de Formosa. Sus estadías en las comunidades se extendieron durante períodos variables, que iban desde las dos semanas hasta los doce meses, de modo continuo durante más de dos décadas. La información sintetizada 
nas ideas relativas a la relación entre humanos y no humanos en función de elementos claves que aparecen en relatos mitológicos y de la forma en que se constituye, desde la perspectiva toba, la persona a partir del cuerpo. Los relatos mitológicos comunes a diversos pueblos chaqueños son uno de los ámbitos privilegiados donde se trasluce que humanos, plantas y animales comparten potencialmente, desde los primeros tiempos, capacidades interiores semejantes, como la volición, la decisión, el lenguaje y la reflexión. La estrella-perro, la serpiente arcoíris o los árboles pilares del cielo aparecen en diversos relatos mitológicos tobas como los agentes responsables de las transformaciones de los diversos mundos que se sucedieron y de la nueva humanidad, que reaparece una y otra vez (Wilbert y Simoneau, 1982). El mundo contemporáneo es, en parte, consecuencia de relaciones e interdependencias entre humanos y no humanos propias de una ontología relacional.

Lo que vale para el mundo y su morfología vale también para la noción de persona entre los tobas a la que nos hemos dedicado en nuestra etnografía comenzada en 1997 (Tola, 2009; 2012). Específicamente, hemos llegado a la conclusión de que en las manifestaciones corporales que la persona va adoptando a lo largo de su vida juega un papel central la agencia no solo de los seres humanos sino también de los no humanos. El cuerpo-persona es susceptible de transformarse a raíz de la acción de entidades no humanas que dejan marcas en él e inciden en su apariencia. Una persona-cuerpo puede combinar elementos y aptitudes tanto humanas como no-humanas, ya que el cuerpo no siempre contiene los elementos que hacen a la persona ni las personas están contenidas exclusivamente dentro del cuerpo. Existen, de hecho, componentes (fluidos corporales, nombres, sombra, etc.) que pueden alejarse momentáneamente del cuerpo y permitir la fusión de cuerpos-personas humanas y no humanas. "Nauoxa» es el término toba que sintetiza las consecuencias que padece la persona-cuerpo humana al no respetar las reglas de comportamiento que rigen las relaciones con los no humanos en momentos especiales de la formación y transformación del cuerpo. Algunos tobas traducen nauoxa (-uoxa: raíz del verbo, 'hacer mal') como 'contagio', en su intento por referirse al proceso de transmisión de las características formales o de comportamiento entre entidades diversas. Un amigo toba tradujo este término como 'influencia', que, a nuestro entender, da más cuenta del proceso implicado. Según su reflexión, el término «influencia» remite al proceso que se lleva a cabo entre dos seres que «cruzaron sus caminos» y que se dejaron una huella en su constitución corporal-vital. Esta huella es vivida como una influencia susceptible de transformar el régimen corporal, los comportamientos y la personalidad de las dos entidades implicadas. Al untarse de grasa de tigre o puma, por ejemplo, los seres humanos estarían adquiriendo propiedades de ese animal, generando así en quienes se les acercan (humanos y animales) las mismas reacciones que suscitan el tigre y el puma. El cuerpo no es entonces la sede de la individualidad en la medida en que

en este apartado deriva de investigaciones de campo extendidas en el tiempo con individuos, familias y comunidades enteras y sobre las cuales la autora ha escrito diversas publicaciones científicas. 
puede ser afectado por (y afectar a) otras entidades y transformar su apariencia y a la persona en su integridad. Lejos de ser un hecho natural, el cuerpo es para los tobas un proyecto colectivo, un espacio socialmente transformado y agenciado que no separa el mundo de la naturaleza del de la cultura ni el humano del animal. El cuerpo no es un envoltorio que encubre una individualidad ni tampoco es en sí un hecho individual. Siempre es necesario un colectivo para hacerse persona y ese colectivo incluye tanto a los seres humanos como a animales, espíritus, dueños de animales y muertos, entre otros.

Todo cuerpo tiene, además, elementos (nombres, fluidos, pensamientos, nqui'i) que lo hacen dependiente de otros o que lo tornan compuesto y descomponible. Él contiene elementos que provienen de otros cuerpos y que no son exclusiva ni únicamente masculinos o femeninos. Nos referimos, por ejemplo, a los pensamientos-sentimientos que circulan entre padres e hijos junto con los fluidos corporales (sangre, semen, leche materna). Ellos son masculinos-femeninos y humanos y no humanos al mismo tiempo. Se suele expresar que el semen (Imale), sustancia que tanto hombres como mujeres producen, es una transformación de la sangre y que, luego, en el cuerpo de la mujer que queda embarazada, se transforma en leche materna que es olida por el bebé lactante y que le permite a este último reconocer a su padre, tal como expresan algunas mujeres tobas. La idea de la persona múltiple se expresa en la importancia dada a la circulación de los fluidos corporales durante la gestación, en los rituales de pubertad y funerarios, en el otorgamiento de nombres, en la absorción conjunta de sustancias durante la convivialidad, en la circulación de emociones vehiculizadas en los fluidos y sustancias, y en las prácticas chamánicas. Durante las curaciones, el pi'oxonaq ${ }^{9}$ o chamán extrae del paciente la enfermedad y así se pertrecha de nuevos poderes o bichos previamente enviados por otro chamán a la víctima. El chamán que los extrae los introduce en su cuerpo y entonces estos poderes «se diluyen, se hacen como humo que queda en la piel del pi'oxonaq», refiere Ino, un joven chamán. Una vez que están en el cuerpo del chamán, estos poderes son constitutivos de su persona: «Son parte tuya», nos explicó él en el año 1999 en una conversación acerca del tema: «son persona mía, sin mí no pueden vivir».

En la metafísica chaqueña en general, el mundo de los seres humanos no está separado de un conjunto de otros seres que hacen juntos el mundo. De hecho, los nombres de las entidades a las que solemos llamar espíritus corresponden, en varias lenguas del Chaco, al nombre con el que se designa a la persona humana. Sin embargo, numerosos investigadores tendieron a concebir, en términos generales, dichas entidades como deidades o teofanías a las que se rendían ceremonias o cultos destinados a mantener ya sea el contacto con «lo sobrenatural» (Métraux, 1944), ya sea la armonía adaptativa entre el hombre y la naturaleza. Huashole' - que es considerada por los tobas como una «mujercita

9. «Pi'oxonaq» se compone de la raíz del verbo, pi'oxon- ('succionar'), y del sufijo -aq, que indica 'el experto en'; el término remite a la succión llevada a cabo para extraer objetos patógenos (palos, sapos, alfileres, piedras) del cuerpo del enfermo. 
del monte» - es descrita por Elmer Miller como «un pequeño ser mítico» (1979), una figura femenina que para Loewen, Buckwalter y Kratz pertenece a una «segunda clase de espíritus» (1997 [1965]: 4). Cuando Miller utiliza el término siỹaxaua (traducido por él al inglés como 'human') lo ubica única y exclusivamente en el plano terrestre del universo, lo que da cuenta de una proyección antropocéntrica según la cual fuera de dicho plano no es posible encontrar rasgos de humanidad en las entidades que los habitan. Cuando se refiere a los seres de otros niveles del cosmos, los denomina grosso modo «espíritu» o «seres poderosos". Sin embargo, en la transcripción que hace de los relatos de sus interlocutores, Miller escribe: «vino a verme un "hombre" diciéndome que me daría el poder de curar. Tenía el cuerpo [...] de un hombre rubio [...]. Cuando llega [...] todos oímos su voz y sus consejos" (1977: 314). ${ }^{10}$ Este ser que se presenta únicamente ante el chamán no solo es llamado hombre sino que también posee atributos corporales propios de todo ser humano. Palavecino (1961), por su parte, presenta relatos de sus interlocutores en los que se lee que los términos que los indígenas usaban en la década de los sesenta no aludían ni a deidades ni a espíritus, sino a personas: «abajo vive gente, gente como nosotros», «cuando morimos el espíritu va a ese lugar bajo tierra y se hace hombre otra vez», «el cielo es como la tierra, hay gente», «por donde entra y sale el sol hay gente, es la gente del sol, tienen el pelo colorado" (Palavecino, 1961: 94). ${ }^{11}$ Sin embargo, cuando Palavecino refiere a la cosmología toba no sostiene que para los indígenas la gente son espíritus. Miguel de los Ríos, al abordar los atributos de lo humano entre los wichí, muestra claramente cómo humanos y no humanos no eran considerados por la mayoría de los autores del área como personas o gente con características semejantes: «capacidad en el actuar (kahjajah) y voluntad, se unen en la figura del viviente. Esta es, por supuesto, la figura humana por excelencia» (1976: 24)..$^{12}$

Pablo Wright (2008) es el primer etnógrafo de la región que, en las décadas de 1980 y 1990, abordó la clasificación de los seres del cosmos sirviéndose de la oposición entre humano y no humano y del concepto de ontología; precisó que, así como los tobas son denominados shiaGawa ('personas'), diversos seres no humanos también pueden ser llamados con este término y tratados como personas según las interacciones con los humanos. La etnografía de Wright es, sin duda, una bisagra que dará inicio a nuevas perspectivas analíticas, y estas, nutridas y en diálogo con etnografías producidas en tierras bajas sudamericanas, transformarán las lecturas religiosas, teológicas, adaptativas y antropocéntricas vigentes hasta ese momento. "Shiyaxaua» es el término que en toba se refiere tanto a los seres humanos como a las personas que poseen una naturaleza semejante a la humana ya que comparten con ellos una vida social similar, capacidades de lenguaje, facultades cognitivas y capacidades de sentir emociones y de ejercer acciones sobre ellos. Estas capacidades están asociadas al

10. El énfasis es nuestro.

11. El énfasis es nuestro.

12. El énfasis es nuestro. 
nqui'i, otro concepto polisémico, que fue traducido como 'alma' pero que remite más a las capacidades cognitivas y afectivas.

Ahora bien, ¿qué implica llamarse como las personas no humanas? Si las personas humanas no son concebidas como las únicas personas, ya que también otros seres son pensados como personas, ¿ellas son las únicas que poseen un cuerpo con todos sus atributos y capacidades? De ningún modo, puesto que otras personas poseen un cuerpo y todo lo que implica tener cuerpo: capacidad de pensar, sentir, desplazarse, hablar, comunicar, actuar voluntaria y conscientemente sobre otro, es decir, tener intencionalidad y agencia. Entonces, estos otros dotados de cuerpo están dotados también de los atributos que definen a una persona. Detengámonos ahora en otra filosofía no occidental en la cual la interdependencia entre los diversos existentes da lugar a la morfología del mundo y de los seres que lo habitan.

\section{El dharma de los seres no sintientes}

El budismo es una de las más antiguas tradiciones espirituales de la humanidad. Nace en el siglo v a. C. con la enseñanza de Siddharta Gautama, quien, tras haber renunciado al reino que le pertenecía por herencia y practicar austeridades por seis años, encuentra la iluminación (o despertar) en una mañana bajo el árbol de Bodhi, en Bodhgaya, India. Esta experiencia es llamada bodhi o despertar, y se caracteriza por una comprensión profunda de la naturaleza del sufrimiento, sus causas, su cesación y el camino que lleva a la cesación. Desde entonces, Siddharta - antiguo príncipe y renunciante - es conocido como Buda y dedica sus siguientes cuarenta años a predicar la comprensión de la realidad revelada en este acontecimiento. Este mensaje es llamado el dharma, que bien puede traducirse como 'verdad', 'ley', 'camino' o 'fenómeno'. Buda entendía el dharma como «profundo, difícil de ver, difícil de entender, pacífico, sublime, más allá de la esfera del mero razonamiento, sutil, para ser experimentado por los sabios» (Gethin, 1998: 30). Asimismo, lo proclamaba como un antídoto al problema fundamental de nuestra existencia, el sufrimiento o dukkha. El mensaje budista se condensa para todas las tradiciones en el sermón de las Cuatro Nobles Verdades, que constituye el primer discurso de Buda, en el que se diagnostica la condición humana de sufrimiento (primera noble verdad), se descubre su origen (segunda verdad), se declara la posibilidad de su extinción (tercera verdad) y se proclama un camino hacia su finalización (cuarta verdad). En su vida, Buda instituye una comunidad de practicantes y seguidores de sus enseñanzas que denomina Sangha. ${ }^{13}$

Uno de los aspectos más sugerentes del budismo es que en el origen de su tradición se encuentra enunciado su propio final: el mensaje budista expresa que la enseñanza de Siddharta florecerá por un tiempo, pero que luego encon-

13. Buda, el dharma y la Sangha son las Tres Joyas o los Tres Refugios del budismo, y constituyen la «piedra angular» para comprender todas las tradiciones que siguen el camino de Buda. 
trará un decaimiento y un final, en el cual las condiciones físicas y morales de los seres entrarán en decadencia. Posteriormente, sobrevendrá un final en el cual todos los seres desaparecerán, hasta que el universo se regenere y un nuevo Buda enseñe el dharma. El budismo ha propuesto, en efecto, una dimensión histórica en la cual el cosmos ha pasado por innumerables ciclos de creación y destrucción, manifestación y no manifestación, sin que sea posible declarar un comienzo y un final definido. Los ciclos se deben a la manifestación del resultado de las acciones de los seres que componen el cosmos, aquello que los budistas llaman karma. Estas ideas sobre los ciclos, el karma y sus efectos sobre la geomorfología del mundo se leen en el Abhidharmakosha, texto del filósofo indio del siglo Iv compuesto por Vasubandhu:

[...] la disposición del universo consiste en tres mil grandes millares de sistemas de mundos. Por el poder de los karmans de los seres, las nubes, reuniéndose, vierten su agua mediante grandes gotas [...]. Debido al crimen intensamente practicado por los hombres las cosas externas, las plantas y la tierra se tornan de poca vitalidad. Una vez que el universo está vacío debido a la extinción del karman de los seres que en él moran [...] siete soles, que van apareciendo gradualmente, queman todo, hasta la tierra y el Monte Sumeru [...]. Así el mundo, que ha desaparecido de esta manera, durante un largo tiempo permanece siendo sólo espacio hasta que nuevamente, por el poder soberano del karman de los seres, vientos suaves se difunden por el espacio, como signos previos de los nuevos mundos que van a aparecer en el futuro (Tola y Dragonetti, en Francia y Tola, 2011: 74-75).

Podríamos citar una gran cantidad de textos en los que se muestra la comprensión budista de un multiverso o pluriverso que está compuesto por infinidad de seres que emergen desde tiempos sin comienzos y que carece de final puntual. La creación de estos universos no obedece a la iniciativa de un dios externo a los seres, sino que se corresponde con la acumulación de las acciones de estos; su karma. ${ }^{14}$ En la cosmología budista, aun cuando las entidades que pueblan el cosmos son numerosas, solo seis de ellas tienen conciencia; estos seis reinos conforman lo que se conoce como samsara o rueda del sufrimiento. La idea central es que los seres que habitan en esta condición están condenados a comportamientos repetitivos guiados por emociones aflictivas (klesas) que generan sufrimiento: los dioses, los espíritus hambrientos, los animales, los seres infernales, los semidioses y los humanos están condicionados a vagar en diversas vidas y ciclos de renacimiento (Gethin, 1998). Se considera a Buda como un ser que ha conseguido liberarse del encadenamiento de estas sucesivas experiencias de dolor e insatisfacción.

14. Tanto la temporalidad que muestra el budismo con sus diferentes ciclos de creación y destrucción como la interdependencia entre los seres y la geomorfología del mundo son puntos que se relacionan con algunas narrativas que emergen en el Antropoceno. La comprensión de una narrativa temporal en la que la tierra ha sufrido diferentes acontecimientos en el transcurso de una larga historia son cuestiones que plantean diversos discursos de lo que se ha llamado «historia profunda» (Smail y Shryok, 2011). Además, la relación entre geomorfología del mundo y acción de los seres que lo componen es retomada en la obra de Latour (2017) con la relevancia que para el autor francés tiene la emergencia de Gaia. 
Lo que nos interesa destacar es que el budismo ha comprendido un cosmos poblado de diversos seres con capacidad de experimentar placer y dolor, lo cual los define como seres sintientes. Aun cuando todas las escuelas budistas sin excepción comprenden un universo poblado por seres conscientes que no son reconocidos por las ontologías naturalistas, tales como devas (dioses), pretas (espíritus hambrientos) o demonios, el dominio de las plantas y los fenómenos naturales es declarado sin consciencia, no sintiente y, por tanto, sin la capacidad de alcanzar la liberación del encadenamiento de causas y consecuencias denominado samsara. Sin embargo, dentro de la tradición budista emergen narrativas que difieren y disputan esta partición. Una de ellas es la que enmarca la tradición zen, en particular aquella que es reconocida como el linaje Soto, cuyo maestro fundador fue el chino Dongshan (807-869), y que el maestro japonés Eihei Dōgen (1200-1253) recibe y lleva al país nipón. Lo que concebimos como esta afinidad y sensibilidad frente a los no humanos (en la tradición budista los no sintientes) y su capacidad de actuar es una inspiración que tiene un recorrido que llega a Dongshan, pero puede ser concebida en la influencia ejercida por autores budistas anteriores. Según Mathew Hall, «con especial atención en las enseñanzas del Sutra del Loto, los académicos budistas chinos en particular comenzaron a enfatizar las conexiones entre las plantas y los humanos en sus discusiones de si la plantas y los árboles podrían alcanzar la iluminación» (2011: 95).

Esta nueva sensibilidad dentro de la tradición budista es encarnada de manera radical en la línea de práctica y reflexión que pasa de Dongshan a Dogen, y con este último impregna la estética del budismo zen en general. En los registros de la tradición zen se dice que la búsqueda de Dongshan comienza con la investigación de la pregunta acerca de cómo los seres no sintientes predican el dharma. Dongshan retomaba la tradición de extender la naturaleza de Buda a todos los seres, sintientes y no sintientes. Una vez Dongshan encuentra a su maestro Yunyan y le pregunta por este dharma de los seres no sintientes, este le responde levantando su abanico; ${ }^{15}$ este gesto performa la actividad y el dharma de los seres no sintientes (Leighton, 2015: 25). Y Yunyan responde citando un texto de la tradición del budismo de la Tierra Pura que dice: «Los pájaros del agua, árboles y bosques, todos sin excepción, recitan el nombre de Buda, recitan el Dharma» (Ibídem: 26). Tras escuchar esas palabras, como muestra de su comprensión, Dongshan escribe:

\footnotetext{
¡Qué maravilloso! ¡Qué maravilloso!

El dharma expuesto por los seres no sintientes es inconcebible.

Escuchando con los oídos, no sonido.

Escuchando con los ojos, comprendes directamente (Ibídem).
}

15. El abanico, el objeto que quizá más a mano tenía Yunyan, era apropiado para mostrar la actividad despierta de los seres considerados no sintientes. 
Cuatro siglos después de Dongshan, Dogen hereda esta narrativa y propone una perspectiva del budismo sumamente novedosa, aunque anclada en la tradición. Uno de los fragmentos más citados de su principal obra, Shobogenzo, en particular el capítulo «Genjokoan», nos permite comenzar la reflexión en torno a los seres no sintientes, cuando señala:

Estudiar el camino al despertar es estudiar el yo. Estudiar el yo es olvidar el yo. Olvidar el yo es ser actualizado por la miríada de cosas. Cuando eres actualizado por la miríada de cosas, tu cuerpo y mente, así como el cuerpo y mente de otros, cae. Ningún rastro de iluminación queda, y este no rastro continúa sin fin (Dogen, 2012: 30).

Dogen propone el camino del despertar como afectación y alteridad radical. El despertar se origina en un acontecimiento crucial y al mismo tiempo ordinario. Dogen se vale de ejemplos como la piedra que golpea el bambú, la visión repentina del ciprés en el jardín o el rugir de los ríos en el valle, los cuales constituyen narraciones de maestros de la tradición budista china que tienen en común un instante de percepción sensible en el cual se presenta una profunda afectación (Dogen, 2012: 87-90). Este hacerse presente del mundo en la experiencia marca una discontinuidad radical en la tendencia del yo a proyectar categorías y conceptos que conforman la percepción rutinaria. En este hacerse presente, el yo es iluminado por la miríada de cosas, de objetos y de seres y la tendencia a confirmar las cosas desde la actividad autocentrada del ego es detenida. En esta detención, las cosas adquieren un lenguaje propio. Es posible escuchar, ver $u$ oler lo que las cosas y seres dicen. ${ }^{16}$

Entonces, ¿qué son los seres no sintientes que exponen el dharma tal como recuerda la pregunta-búsqueda de Dongshan? Dentro de la perspectiva budista en la cual Dogen se incluye, todos los seres son naturaleza búdica: todos los seres son Buda. ${ }^{17}$ No solo poseen un potencial para desarrollar esta naturaleza, sino que además son Buda; su expresión es Buda. Así pues, al ser Budas es posible que los seres no sintientes expongan el dharma. Dogen es enfático al afirmar que no se logra escuchar el dharma de los seres no sintientes a través del lenguaje corriente. Tanto la capacidad cognitiva y perceptiva como el lenguaje deben virar de hábitos antropocéntricos. La exposición del dharma o la enseñanza de los seres no sintientes requiere una dislocación de nuestras competencias perceptivas comunes:

No debes pensar que los seres no sintientes exponen el Dharma en la manera en que los seres sintientes exponen el Dharma. Si asumes que los seres no sintientes deben ser como los seres sintientes en sus voces y en la manera en que exponen el Dharma, y así, conjeturar las voces

16. Este lenguaje de las cosas remite directamente a la comprensión budista de la interdependencia entre todos los existentes (pratitya samutpada), la cual es actualizada en la actividad despierta y responsable del practicante en el mundo.

17. Sin embargo, la inclusión de Dogen entre los seguidores de la tradición Tathagatagharba (Naturaleza Búdica) en el budismo debe ser matizada. Su afirmación de la naturaleza búdica en todos los seres no conlleva una aceptación fatalista del mundo, posición en la que algunas tradiciones que van en esta dirección caen; o bien, un sesgo antinominalista que relega la ética a prácticas inferiores. 
de los seres no sintientes en términos de estos seres sintientes, esto es contrario al Dharma (citado en Kim, 2004: 83).

Al ser confirmado por las cosas, el humano accede a percibir un lenguaje, una lógica distinta, aprende a cohabitar con otros seres. En uno de los fragmentos del Shobogenzo, llamado «El Sonido del Valle, el Color de las Montañas", Dogen cuenta la historia del laico Dongpo, quien, tras escuchar a su maestro Changzong hablar sobre la enseñanza del dharma de los seres no sintientes, oye por primera vez los sonidos del valle. Tras este despertar, Dongpo escribe:

Los sonidos del valle son la lengua larga y amplia.

El color de las montañas no es otro que el cuerpo incondicionado.

Ochenta y cuatro mil versos se han escuchado en la noche.

¿Qué puedo decir de esto en el futuro? (Dogen, 2012: 86).

Los seres que en la condición humana habitual se consideran objetos, no sintientes, son capaces de enseñar la verdad última de la realidad: el dharma. Es por ello por lo que, en un bello fascículo del Shobogenzo, Dogen presenta «El Sutra de las Montañas y los Ríos». ${ }^{18}$ Parte del Sutra es una investigación en la manera en que las montañas caminan: «Si dudas del caminar de las montañas, no conoces tu propio caminar; no es que no camines, sino que no conoces o comprendes tu propio caminar» (Dogen, 2012: 155). En este fascículo Dogen es explícito en la manera activa que toman las montañas y aguas vistas desde una perspectiva no antropocéntrica. El movimiento de las montañas así como el dharma de los seres no sintientes solo puede ser comprendido a través de una dislocación de nuestras facultades cognitivas y lingüísticas habituales. La cuestión es, pues, zarandear un poco nuestra petrificada noción de lo que consideramos de manera automática sintiente y no sintiente; esta es la práctica a la que invita Dogen y parte de la tradición budista.

\section{Reflexiones finales}

A lo largo de este artículo hemos intentado problematizar la narrativa científica que da origen al concepto de Antropoceno a través de, por un lado, alternativas que - desde las ciencias sociales - proponen el Antropoceno parche, Gaia y el Chtuluceno como ejemplos en los cuales diversas agencias no humanas son tomadas en serio en cuanto que sujetos partícipes de esta nueva era de crisis global. Por otro lado, hemos incluido en nuestro análisis del Antropoce-

18. Se denominan "sutra» los antiguos discursos, las antiguas enseñanzas pronunciadas por Buda. Según Taigen Leighton, este escrito de Dogen puede ser traducido del japonés al inglés como «The Landscape Sutra» ('el sutra del territorio'), ya que montañas y ríos son la denominación japonesa para el paisaje en general (Leighton, 2014). Creemos que en este texto se explicita de manera clara el carácter activo, dinámico, de los diferentes seres del mundo declarados por la tradición como no sintientes. 
no dos metafísicas no occidentales que, desde historias y perspectivas diversas, convergen en ciertas propuestas, también alternativas al discurso de las ciencias de la Tierra. Ellas son el budismo zen reelaborado por Dogen y la filosofía amerindia, específicamente, aquella del pueblo qom o toba del Chaco argentino.

La propuesta de Dogen sobre el papel de los seres no sintientes en la enseñanza del dharma no solo da lugar a un marco estético y práctico diferente en algunos puntos de la cosmovisión budista ortodoxa, sino que también amplía la intuición de Latour, Haraway y Tsing respecto de la necesidad de entablar una conversación y generar nuevos relatos en esta época de gran pérdida y desolación. Se debe señalar que la perspectiva en la cual se enmarca Dogen no solo constituye una elaboración teórica sobre la inadecuación de la distinción entre sintiente y no sintiente, sino que pretende transformar, de manera radical, las habilidades perceptivas y afectivas de los practicantes mismos. La práctica de shikantaza o solo sentarse en la cual los practicantes zen simplemente se sientan y dejan que se asiente la experiencia en la base profunda de la corporeidad y la respiración es una de las maneras más profundas que Dogen propone para detener el automatismo experiencial en el cual funciona el gran divisor. Cabe señalar que, en el solo sentarse, el practicante deja caer cuerpo y mente ${ }^{19}$ para recuperar un estado que se supone más primario y fundamental que el ego individualizado y separado, donde la comunicación con un mundo amplio de perspectivas se hace posible. Se podría imaginar una comparación en la que el despertar al cual el practicante zen aspira se conecta, en algunos puntos, con la experiencia primigenia de comunicación entre seres con diferentes perspectivas a la cual el chamán suele tener acceso. Este punto nos lleva a comprender el budismo desde una óptica animista más que desde un punto de vista analogista, tal como señala Descola (2005), para quien el budismo y otras filosofías orientales ofrecerían una alternativa holística al universalismo truncado de los modernos. La visión toba acerca de la interdependencia entre humanos y no humanos, y de la posibilidad de que ambos colectivos entablen relaciones de diversa índole por el hecho de compartir una interioridad, también constituye un ejemplo en pleno Antropoceno.

La metafísica qom de las relaciones y la postura budista de Dogen desafían la Gran División naturaleza/cultura y constituyen un llamamiento a recomponer las capacidades y habilidades afectivas, perceptivas y cognitivas en torno a aquellos que los naturalistas hemos declarado como no sintientes y no humanos. Es por ello por lo que ambas propuestas permiten pensar, por un lado, un proyecto político que incluye diferentes voces (la de los no sintientes y la de los no humanos) y, por otro, una ética ampliada. El proyecto filosófico, ético y político que subyace a ambas narrativas crea zonas de comunicación que permiten

19. «Dejar caer cuerpo y mente» es una de las frases que Dogen utiliza para expresar este estado de despertar y que tiene que ver con una radical apertura en la cual el practicante, entre otros efectos, reconoce un aspecto vivo del mundo y sus cosas (Heine, 2012). Esta experiencia está íntimamente relacionada con la afectación radical que antes mencionamos, en la cual el yo, antes que iluminar las cosas, es iluminado por ellas. 
relaciones de cuidado y cohabitación a raíz de la interdependencia entre todo lo existente. En esta misma línea, la antropóloga y humanista ambiental Bird Rose señala:

Un efecto de abrirse uno mismo, como humano, será despejar el mito de lo que no tiene mente, no a través de un relato lógico, sino a través de la experiencia de ser uno entre muchos, en un mundo ya repleto de consciencia. Abriendo el propio yo a otros y comprendiéndoles como seres comunicativos, uno se pone a sí mismo en una posición capaz de experimentar comunicación (2013: 97).

En esta época en la que, tal como lo recuerdan Tsing (2017a) y otros autores, diversos fantasmas y monstruos recorren y componen los terrenos desolados de una tierra que ha sido despojada, saqueada e irrespetada hasta el cansancio, las voces que hemos presentado conminan a prestar renovada atención a otras perspectivas no hegemónicas con miras a revertir la negligencia que ha guiado las facultades perceptivas y prácticas de los humanos en relación con estos diversos no humanos. Recalcamos la paradoja que presenta el Antropoceno: un momento que señala una profunda desaparición de las diferentes agencias con las cuales, históricamente, el humano ha convivido y creado mundos llama a prestar atención y crear relaciones de respeto y cuidado en nuestras prácticas y perspectivas. Como señalan diversos autores, los estudios sobre el Antropoceno adolecen de un impulso colonial y generalizador que es importante no obviar. La manera en que prestamos atención a otras agencias y las teorizamos en los actuales discursos críticos sobre el Antropoceno bien puede nutrirse de prácticas y maneras de pensar la relación con estos no humanos desde cosmologías y comprensiones distantes en tiempo y espacio. Presentamos en este texto un primer acercamiento a dos metafísicas no occidentales que puede aportar a la actual preocupación por afinar las habilidades de escucha para así poder reflexionar con otros seres sobre la construcción de mundos donde se actualicen vínculos de respeto y curiosidad por aquello que nos excede. El Antropoceno quizá permita hallar un lugar de encuentro en el que, desde el punto de vista ontológico y práctico, otras narrativas puedan aportar a la construcción de relaciones nuevas entre humanos y no humanos, en una coexistencia no exenta de fricciones. Apuntamos que estas relaciones, tal como se lee en las ontologías amerindias, deberán estar guiadas por el respeto, el cuidado y una cierta etiqueta y ética que habrá que saber extender más allá de las fronteras nativas o de nichos especializados.

\section{Bibliografía}

AtLeO, Richard (2011). Principles of tsawalk: An indigenous approach to global crisis. Vancouver: University of British Columbia Press.

BIRD, Rose (2013). «Val Plumwood's Philosophical Animism: attentive interactions in the sentient world». Environmental Humanities, 3, págs. 93-109. 
Crutzen, Paul y Stoermer, Eugene (2000). «The Anthropocene». Global Change Newsletter, págs. 17-18.

DANOWSKI, Deborah y VIVEIROS DE CASTRO, Eduardo (2019). ¿Hay mundo por venir? Buenos Aires: Caja Negra.

ChAKRABARTY, Dipesh (2009). «The climate of history: four theses». Critical Enquiry, 35, págs. 197-222.

Descola, Philippe (2005). Par-delà nature et culture. París: Gallimard.

Descola, Philippe (2014). La composition des mondes. Entretiens avec Pierre Charbonnier. París: Flammarion.

DescolA, Philippe (2018). Una antropología alterada por la alteridad. Buenos Aires: Palabra Reversa.

Francia, Timoteo y Tola, Florencia (2011). Reflexiones dislocadas. Pensamientos políticos y filosóficos qom. Buenos Aires: Rumbo Sur / Universidad de Buenos Aires.

DogEN, Eihei (2010). Dogen's extensive record: A translation of the Eihei Koroku. Boston: Wisdom Publications.

Dogen, Eihei (2012). Treasury of the True Dharma Eye: Zen Master Dogen's Shobogenzo. Boulder: Shambala.

Dooren, Thom van; BIRD R., Deborah y Chrulew, Matthew (2017). Extinction studies: Stories of time, death and generations. Nueva York: Columbia University Press.

FINNEY, Stanley C. y EDWARDS, Lucy E. (2015). «The "Anthropocene" epoch: Scientific decision or political statement?». GSA Today, 26, págs. 4-10.

Gethin, Rupert (1998). The foundations of Buddhism. Oxford: Oxford University Press.

HaLL, Mathew (2011). Plants as persons. Nueva York: SUNY University Press.

Hamilton, Clive; Bonneuil, Cristophe y Gemenne, Francois (2015). The Anthropocene and the global environmental crisis. Nueva York: Routledge.

HARAWAY, Donna (1991). Simians, cyborgs and women. Londres: Free Association Books.

HARAWAY, Donna (2008). When species meet. Mineápolis: University of Minessota Press.

HARAWAY, Donna (2016). Staying with trouble: Making Kin in the Chthulucene. Durham: Duke University Press.

HEINE, Steven (2012). "What is on the other side? Delusion and relization in Dogen's "Genjokoan"». En: HeINE, S. (ed.). Dogen. Textual and Historical Studies. Oxford: Oxford University Press.

KIM, Hee-Ji (2004). Eihei Dogen, mystical realist. Boston: Wisdom Publications.

KolBERT, Elizabeth (2014). The sixth extinction: An unnatural History. Nueva York: Henry Holt.

LATOUR, Bruno (2012 [1991]). Nunca fuimos modernos. Buenos Aires: Siglo XXI Editores.

LATOUR, Bruno (2017). Cara a cara con el planeta. Buenos Aires: Siglo XXI Editores.

LeIGHTON, Taigen Dan (2015). Just this is it. Boston: Shambala Publications.

LOEWEN, Jakob; BuCKWALTER, Albert y KRATZ, James (1997 [1965]). «Shamanism, illness and power in Toba church life». Practical Anthropology, 12, págs. 250-280.

Lovelock, James E. y MARGULIS, Lynn M. (1974). «Atmospheric homeostasis by and for the biosphere: The Gaia hypothesis», Tellus, 26, págs. 2-10.

Lenton, Timothy; Dutreuil, Sebastien y Latour, Bruno (2020). "Life on Earth is hard to spot», The Anthropocene Review, 7, 3, págs. 248-272.

MÉTRAuX, Alfred (1944). «Nota etnográfica sobre los indios mataco del Gran Chaco argentino", Relaciones, 4, págs. 7-18. 
MiLLER, Elmer (1977). «Simbolismo, conceptos de poder y cambio cultural de los tobas del Chaco argentino». En: HeRmitTE, E. (comp.). Procesos de articulación social. Buenos Aires: CEAL.

MILLER, Elmer (1979). Los tobas argentinos: armonía y disonancia en una sociedad. México: Siglo XXI.

Moore, Jason (2016). Anthropocene or Capitalocene? Nature, History, and the crisis of capitalism. Oakland, California: PM Press.

Morton, Timothy (2018). Hiperobjetos. Argentina: Adriana Hidalgo.

PALAVECINO, Enrique (1961). «Algo sobre el pensamiento cosmológico de los indígenas chaquenses». Cuadernos del Instituto Nacional de Investigaciones Folklóricas, 2, págs. 93-95.

ROCKSTRÖM Johan et al. (2009). «A safe operating space for humanity». Nature, 46, págs. 472-475.

StEngERS, Isabelle (2017). En tiempos de catástrofe. Barcelona: Futuro Anterior Ediciones.

SERRES, Michel (2004). El contrato natural. Valencia: Pre-Textos.

SKAFISH, Peter (2016). «"The metaphysics of extra-moderns", a conversation with Viveiros de Castro». Common Knowledge, 22 (3), págs. 393-414.

SmAlL, David y ShrYok, Andrew (eds.) (2011). Deep History. The architecture of past and present. Berkeley: University of California Press.

STEFFEN, Will et al. (2015). «The trajectory of the Anthropocene: The great acceleration». The Anthropocene Review, págs. 1-18.

TOLA, Florencia (2009). Les conceptions du corps et de la personne dans un contexte amérindien. Indiens Toba du Gran Chaco sudaméricain. París: L'Harmattan.

TOLA, Florencia et al. (2019). «Entre el futuro que ya llegó y el pasado que nunca pasó: diplomacias chaqueñas en el Antropoceno». Mana, 25, 3, págs. 773-800.

TozZINI, Alma (2011). «Pagarnos con lo propio. Trayectorias comunes en territorios desgajados». En: VALVERDE, Sebastián et al. Procesos históricos, transformaciones sociales y construcciones de fronteras. Aproximaciones a las relaciones interétnicas (Estudios sobre Norpatagonia, Argentina y Labrador, Canadá). Buenos Aires: Universidad de Buenos Aires, págs. 275-305.

TsING, Anna (2015). The mushroom at the End of the World: On the Possibility of Life in Capitalist Ruins. Princeton, Nueva Jersey: Princeton University Press.

TsING, Anna (2017a). Arts of living on a damaged planet. Minnesota: University of Minnesota Press.

TsING, Anna (2017b). «A threat to Holocene resurgence is a threat to livability». En: BRIGHTMAN, Marc y LeWIS, Jerome (eds.). The anthropology of sustainability. Nueva York: Palgrave Mcmillan, págs. 51-65.

TRISCHLER, Helmut (2017). «El Antropoceno: ¿un concepto geológico o cultural, o ambos?». Desacatos, 54, págs. 40-57.

Tsing, Anna; Mathews, Andrew y BunBadT, Nils (2019). «Patchy Anthropocene: Landscape structure, multispecies history, and the retooling of anthropology. An introduction to supplement 20». Current Anthropology, 60, 20, págs. S186-S197.

ViveIROS DE CASTRO, Eduardo (1996). «Os pronomes cosmológicos e o perspectivismo ameríndio». Mana, 2, 2, págs. 115-144. 
Viveiros de CASTRo, Eduardo (2002). A inconstancia da alma selvagem. São Pablo: Cosac y Naify.

ViveIROS DE CASTRO, Eduardo (2019). "On models and examples: engineers and bricoleurs in the Anthropocene». Current Anthropology, 60, 20, págs. S296-S308.

WILBERT, Johannes y SIMONEAU, Karin (1982). Folk literatures of the Toba Indians. Los Ángeles: University of California.

Williams, Paul y Tribe, Anthony (2000). Buddhist thought. Nueva York: Routledge.

Fecha de recepción: 8 de junio de 2020

Fecha de aceptación: 27 de noviembre de 2020

Fecha de publicación: 30 de junio de 2021 